delayed and the drug treatment is continued.

The newer anticonvulsant, lamotrigine (Lamictal ${ }^{\circledR}$ ), chemically unrelated to conventional AEDs, and introduced as adjunctive therapy of partial seizures, may also cause skin rash, especially within the first six weeks of therapy, in patients receiving concomitant VPA, and in those receiving doses higher or escalated faster than generally recommended. (Glaxo Wellcome product information).

AED-induced skin rash in children treated with CBZ and lamotrigine is reviewed in Progress in Pediatric Neurology III, 1997, pp 143-146; and VOL II, 1994, pp 107-109; PNB Publishers, Chicago.

\title{
DIET, CARNITINE, AND VALPROATE-INDUCED AMMONEMIA
}

The effect of a protein-rich meal (45 g protein) before and after Lcarnitine $(50 \mathrm{mg} / \mathrm{kg} /$ day) for 7 days in 11 epileptic children treated with valproate (VPA) was studied in relation to the magnitude and duration of the VPA-induced hyperammonemia at the University of Wisconsin School of Pharmacy and Department of Neurology, Madison, WI. After a protein meal, the 2-hour plasma ammonia level was increased by $86 \%$ over baseline before carnitine administration compared to $38 \%$ after carnitine. Ammonia levels approached baseline at 4 hours after a protein meal and were not related to changes in VPA concentrations. (Gidal BE, Inglese CM, Meyer JF, Pitterle ME, Antonopolous J, Rust RS. Diet- and valproate-induced transient hyperammonemia: effect of L-carnitine. Pediatr Neurol May 1997;16:301-305). (Respond: Dr Gidal, University of Wisconsin School of Pharmacy and Department of Neurology, 425 N Charter St, Madison, WI 53706).

COMMENT. VPA increases plasma ammonia in almost $50 \%$ of children treated. The degree of hyperammonemia is related to diet. It is exacerbated by a protein rich meal, and the postprandial transient elevation of plasma ammonia is significantly reduced by L-carnitine administration and is unrelated to changes in VPA concentration. Both fasting and 2-hour postprandial plasma ammonia levels should be measured to determine the magnitude of a VPAinduced hyperammonemia.

Valproate-induced liver failure is reported in one of two siblings with Alpers disease treated at the University of Minnesota, Minneapolis. (Schwabe MJ, Dobyns WB, Burke B, Armstrong DL. Pediatr Neurol May 1997;16:337-343). Both were developmentally delayed and suffered from seizures from 5 years of age. The proband receiving VPA for only 5 days had minimal liver abnormalities at autopsy at age 8 years. The younger brother treated with VPA for 4 weeks developed acute liver necrosis and died 5 weeks after admission. VPA is not recommended in children with suspected Alpers disease, characterized by developmental delay, ataxia, and epilepsia partialis continua.

\section{GABAPENTIN-INDUCED CHOREOATHETOSIS}

Two institutionalized, severely retarded adults, aged 42 and 41 , with intractable epilepsy, developed choreoathetosis within 14 days when gabapentin in dosages of 1200 to $1800 \mathrm{mg} / \mathrm{d}$ were added as adjunctive therapy to valproic acid or phenytoin, in a report from University of Texas Southwestern Medical Center, Dallas, and Denton State School, Texas Mental Health and MR System. In case 1, also receiving valproic acid, intermittent choreoathetosis occurred for many weeks after gabapentin was discontinued, 